\title{
Awareness and Knowledge of Oral Cancer among Dental Practi- tioners of Bhopal, India - A Cross-Sectional Study
}

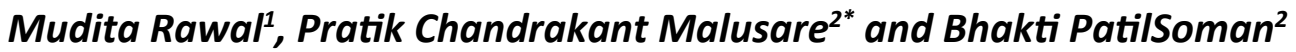 \\ ${ }^{1}$ Private Practice, Gujrat, India \\ ${ }^{2}$ Oral Medicine \& Radiology Department, G.D Pol Foundation Y.M.T Dental College, Navi Mumbai, India
}

*Corresponding author: Dr. Pratik Chandrakant Malusare, Lecturer, Oral Medicine \& Radiology Department, G.D Pol Foundation Y.M.T Dental College, Kharghar, Navi Mumbai-410210, India, Tel: 91-8369030834, E-mail: pratsmalu@gmail.com

\begin{abstract}
Introduction: Oral and pharyngeal cancers are largely preventable and can be successfully treated when diagnosed at an early stage. Lack of dental practitioner knowledge has been shown to contribute to delays in referral and treatment. Early detection of oral cancers makes them more amenable to treatment, thus reducing morbidity and allowing the greatest chance of cure. The malignancy is often detected at advanced stages, when more aggressive therapies, often with poor and devastating outcomes for the patient, are needed.

Aims and objectives: To assess the awareness and knowledge of oral cancer and its early signs and risk factors in dental practitioners.

Materials and methods: The data was collected using a self-administered questionnaire related to oral cancer awareness, oral examination habits, delivery of advice on oral cancer risk factors, knowledge of oral cancer risk factors and clinical appearance, preferred point of referral. The questionnaire was given to 100 dental practitioners.

Results: The result showed that Dental Practitioners are generally knowledgeable of oral cancer risk factors and diagnostic concepts, but some gaps existed in their knowledge.

Conclusion: This survey demonstrated that dental practitioners are well aware of risk factors associated with oral cancer but there is a lack of knowledge about it and it also demonstrated their understanding of their needs in this area and a willingness to undertake additional education.
\end{abstract}

\section{Introduction}

Oral cancer is major public health problem in the Indian subcontinent, where it ranks among the top three types of cancer in the country [1]. Oral cancers include those of the lip, tongue, salivary glands and other sites in the mouth, whereas pharyngeal cancers affect the nasopharynx, oropharynx and hypopharynx. Most oral cancers are attributed to the use of tobacco products that are smoked or chewed. The combined use of tobacco and alcohol significantly increases the risk of these cancers. Other risk factors include actinic radiation for lip cancer, a lack of fruits and vegetables in the diet, and human papillomavirus [2]. The oral cavity is usually easily accessible for examination and thus offers the potential for opportunistic screening for intraoral cancer. For opportunistic screening to be effective, it is vital that primary care clinicians should be aware of the variety of presentations of malignant and premalignant disease. Treatment at an early stage improves prognosis. Dentists are qualified to opportunistically screen for oral cancer and to provide preventive advice such as cessation of habits and counselling interventions during routine examinations. It is vital that dentists have accurate knowledge about oral cancer to identify individuals at risk, examine the mouth to document tissue changes and provide appropriate interventions, thus potentially contributing to the reduction in oral cancer incidence, morbidity and mortality. Dentists are professionally responsible for determining whether patients are at risk of developing oral cancer, as well as for providing a comprehensive oral cancer examination for their patients. Dentists are important in primary and secondary prevention of oral cancer; Therefore, assessing their knowledge, opinions and practices is crucial. The purposes of this study was to assess and describe dental

Citation: Rawal M, Malusare PC, PatilSoman B (2018) Awareness and Knowledge of Oral Cancer among Dental Practitioners of Bhopal, India - A Cross-Sectional Study. Int J Oral Dent Health 4:056. doi.org/10.23937/2469-5734/1510056

Accepted: August 01, 2018: Published: August 03, 2018

Copyright: (C) 2018 Rawal M, et al. This is an open-access article distributed under the terms of the Creative Commons Attribution License, which permits unrestricted use, distribution, and reproduction in any medium, provided the original author and source are credited. 
practitioners understanding of risk and diagnostic factors related to oral cancer and to determine their opinions about their professional knowledge to prevent and control oral cancer.

\section{Aims and Objectives}

- To assess the awareness of oral cancer in dental practitioners.

- To assess the knowledge of oral its early signs and risk factors in dental practitioners.

- To determine their opinions about their professional knowledge to prevent and control oral cancer.

\section{Materials and Methods}

- This cross-sectional study comprises of randomly selected 100 dental practitioners of Bhopal.

- Each dental practitioner were given questionnaire according to Carter \& Ogden [3] (Annexure) related to oral cancer awareness, oral examination habits, delivery of advice on oral cancer risk factors, knowledge of oral cancer risk factors and clinical appearance, preferred point of referral.

- Written consent were obtained from them.

\section{Results}

A cross-sectional, descriptive, questionnaire-based survey method was conducted on study group comprised of randomly selected 100 dental practitioners with Bachelor of Dental Surgery (BDS) and Master of Dental Surgery (MDS) qualification among them. 39\% were males and $61 \%$ females with age ranging from 25 to 45 . After taking consent each dentist were provided with questionnaire containing 10 questions related to oral cancer awareness, risk factors, clinical appearance, referral point etc. The results were hypothesized with response scores which significantly related to oral cancer awareness, risk factors, clinical appearance, referral point among the study participants. The data were transformed from precoded proforma to a computer

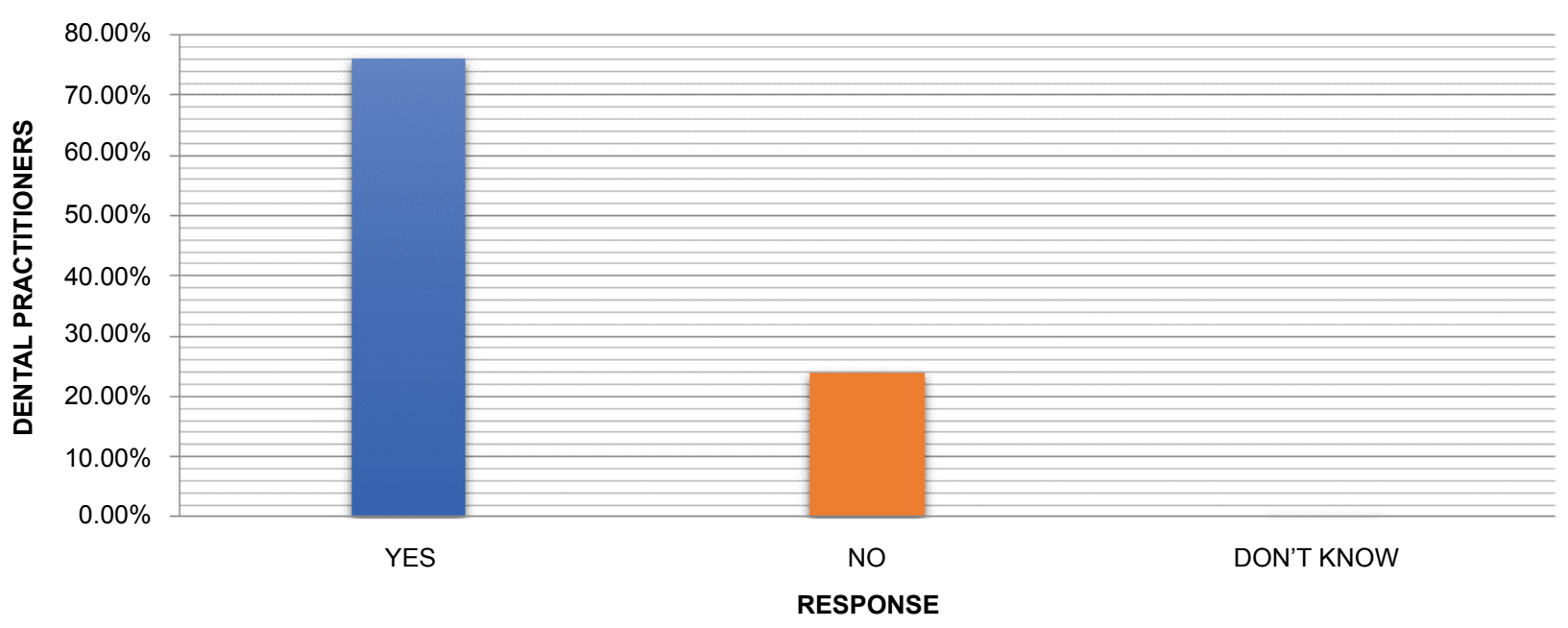

Figure 1: Examination of patient's oral mucosa routinely by dental practitioners.

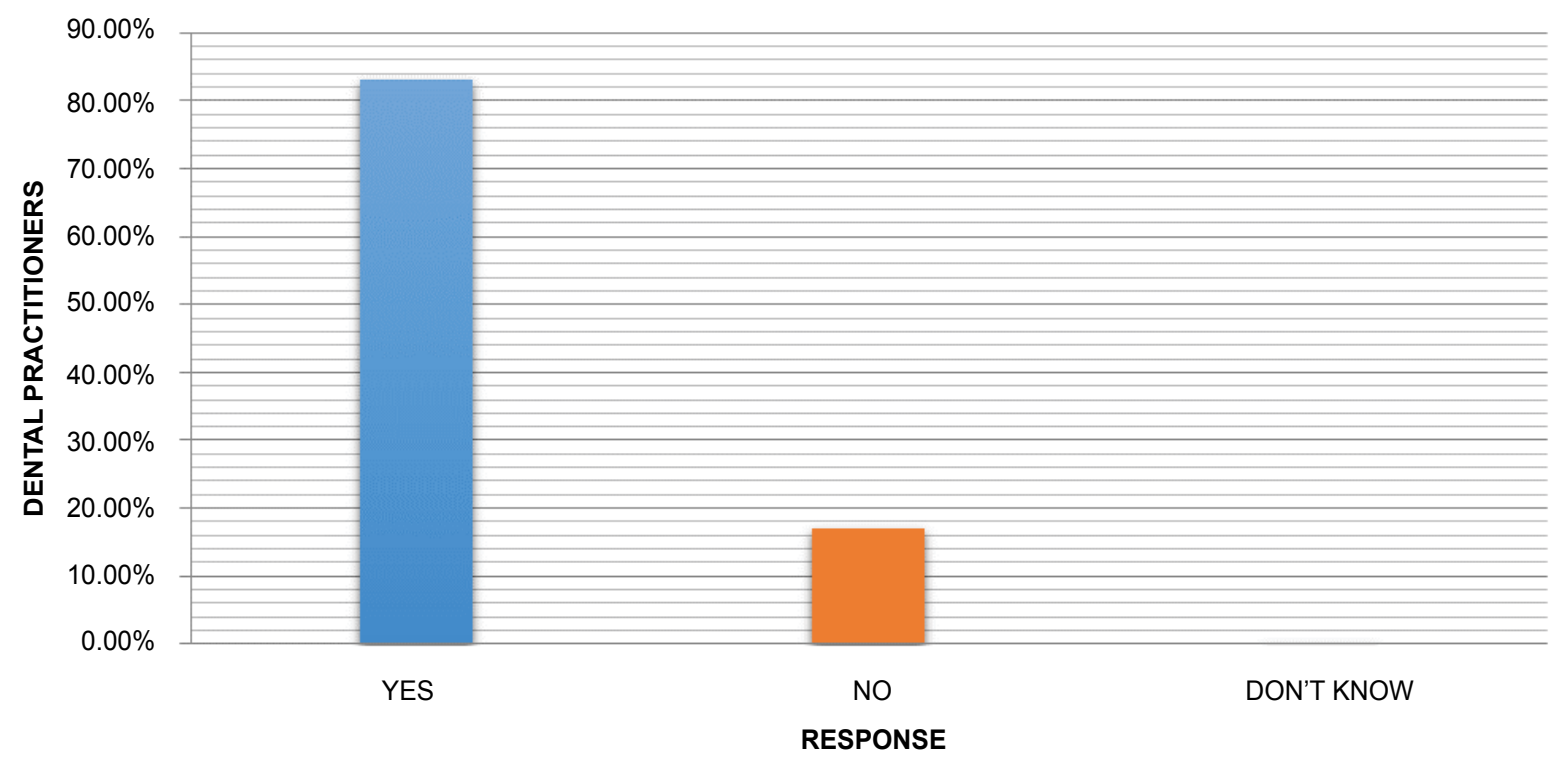

Figure 2: Screening the oral mucosa if the patients are in high risk categories. 
through a master file which was created for the purpose of data analysis. Statistical software SPSS for Windows, Version 16.0. (SPSS Inc. Released 2007, Chicago, SPSS Inc.) system was used for analysis. Microsoft Word and Excel sheet were used to generate tables and graphs. The study comprised of $60 \%$ MDS and $40 \%$ BDS. According to the study, in the very first questions it was found that $76 \%$ of the dental practitioners routinely examine oral mucosa of their patients whereas $24 \%$ of the dental practitioners do not examine oral mucosa routinely (Figure 1). $83 \%$ of the dental practitioners routinely screen oral mucosa of patients who are in high risk categories (tobacco consumption history, hereditary history of oral cancer) (Figure 2). In this study the knowledge of risk factors of oral cancer was also asked in our questionnaire in which it was found that $53 \%$ of the dental practitioners considered smoking as main risk for oral cancer whereas $23 \%$ considered smokeless tobacco as main risk factor (Figure 3). $67 \%$ of the dental practitioners had an opinion that the risk of oral cancer increases with age. (Figure 4) As diagnosing oral cancer is very important on clinical appearance so the question was asked regarding knowledge of diagnosing oral cancer from clinical appearance. It was really surprising response that $43 \%$ of them felt unsure regarding diagnosing of oral cancer from clinical appearance (Figure 5). Dental practitioners found $39 \%$ of oral cancer associated with non-healing ulcer, $27 \%$ associated with red patch, $17 \%$ associated growth of abnormal tissue (Figure 6). On asking them regarding referral point for treatment of their patients, $66 \%$ considered cancer hospital, $22 \%$ considered oral surgery and $13 \%$ considered oral medicine respectively as referral point for their patients (Figure 7). Finally, $85 \%$ of the dental practitioners showed interest in

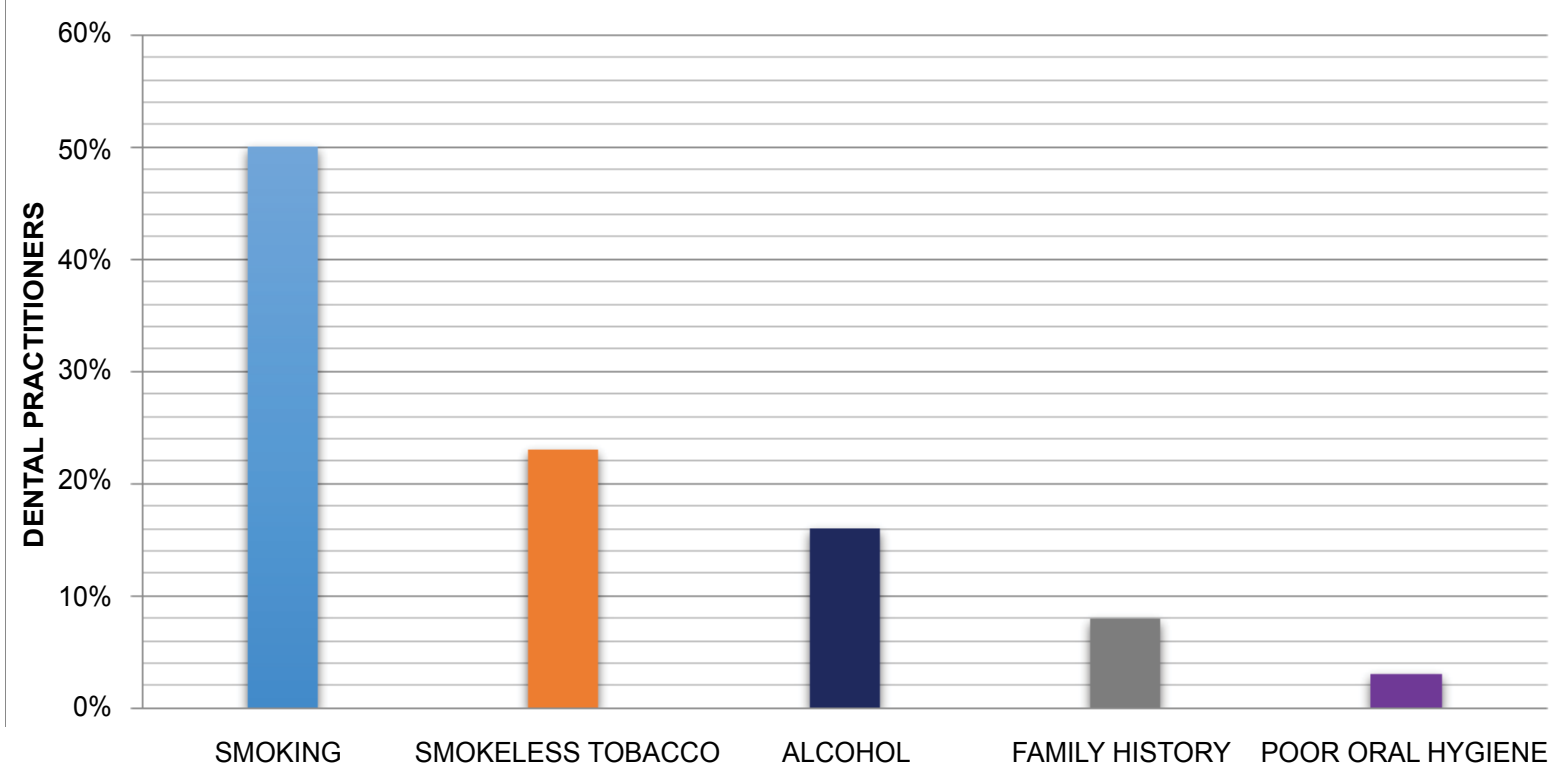

Figure 3: Main risk factors for oral cancer.

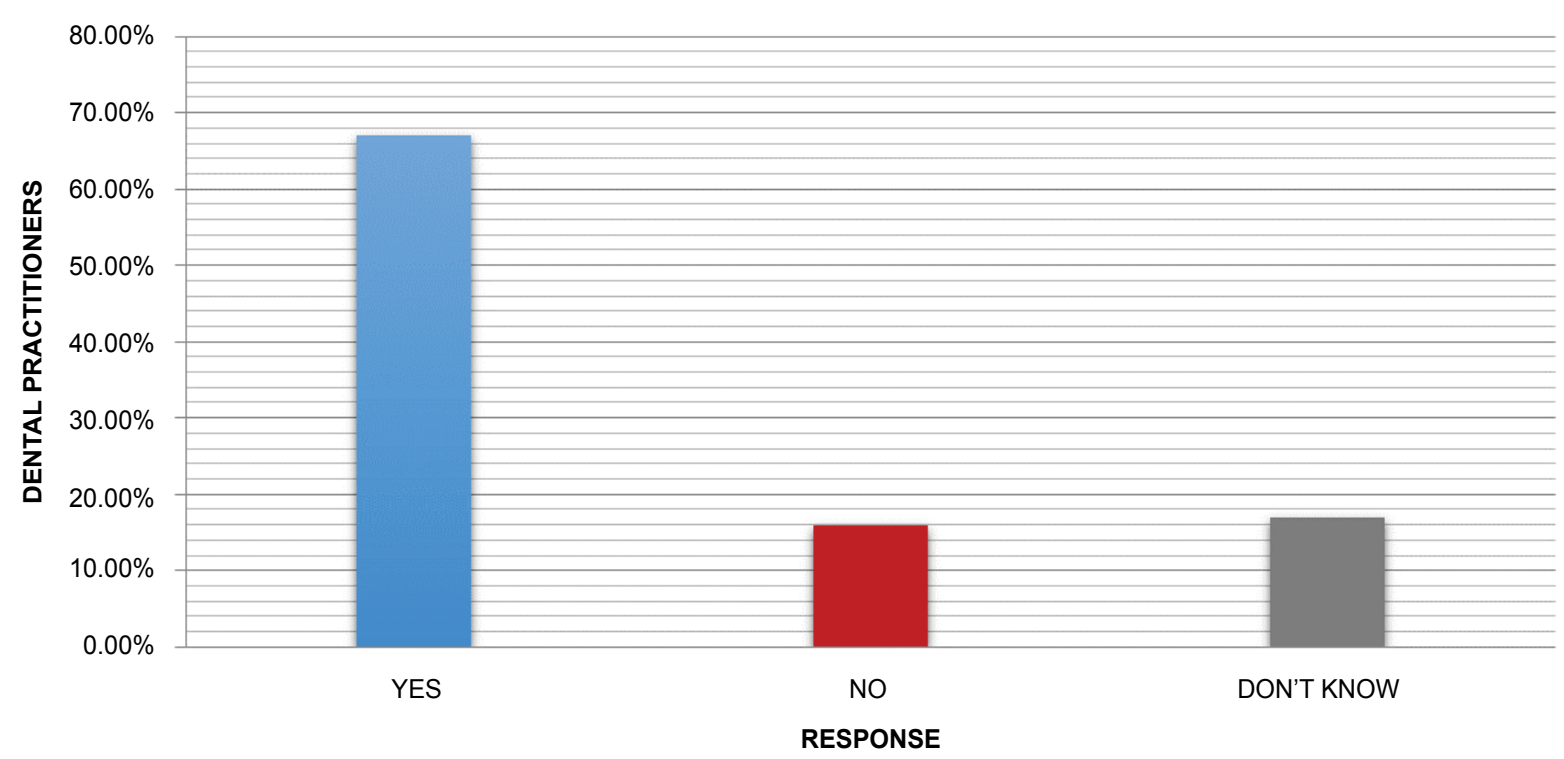

Figure 4: Risk of oral cancer increase with age. 


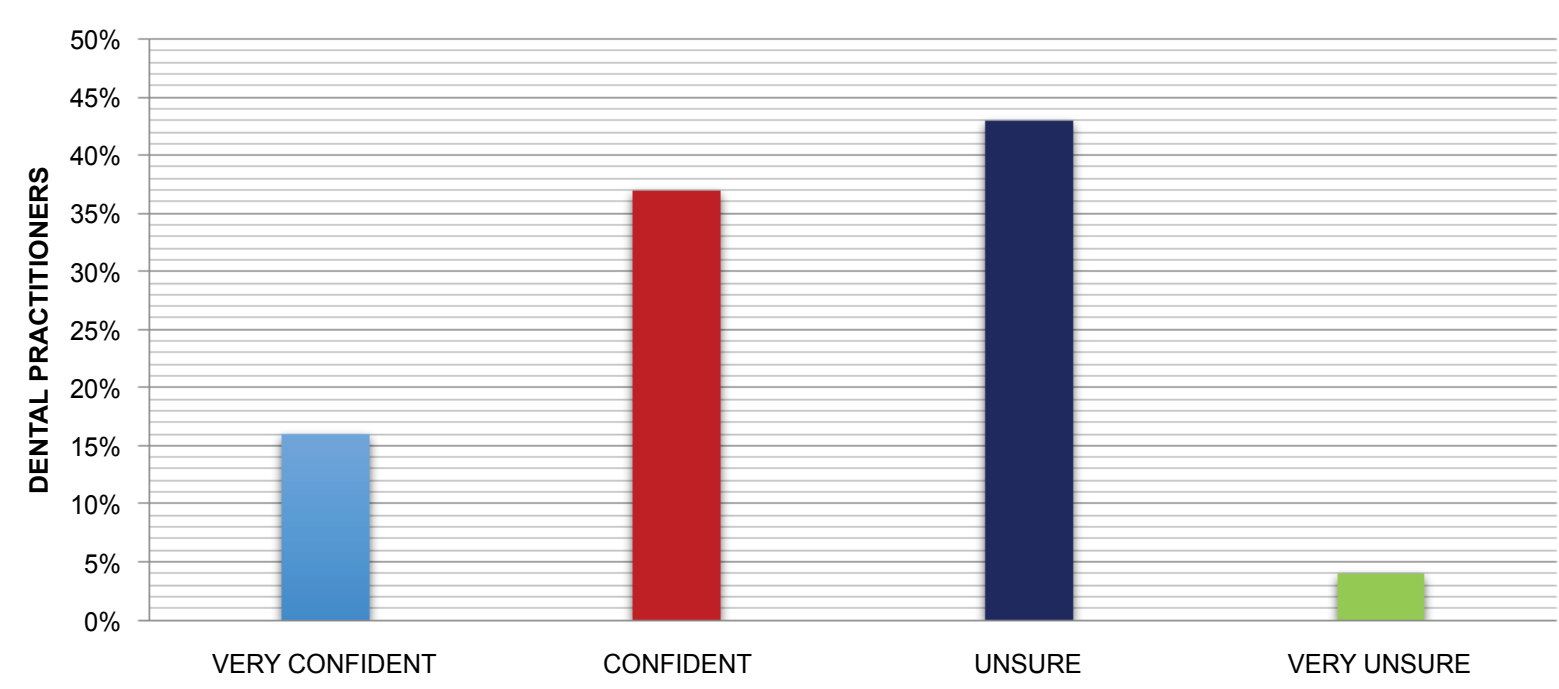

Figure 5: Diagnosing of oral cancer from clinical appearance.

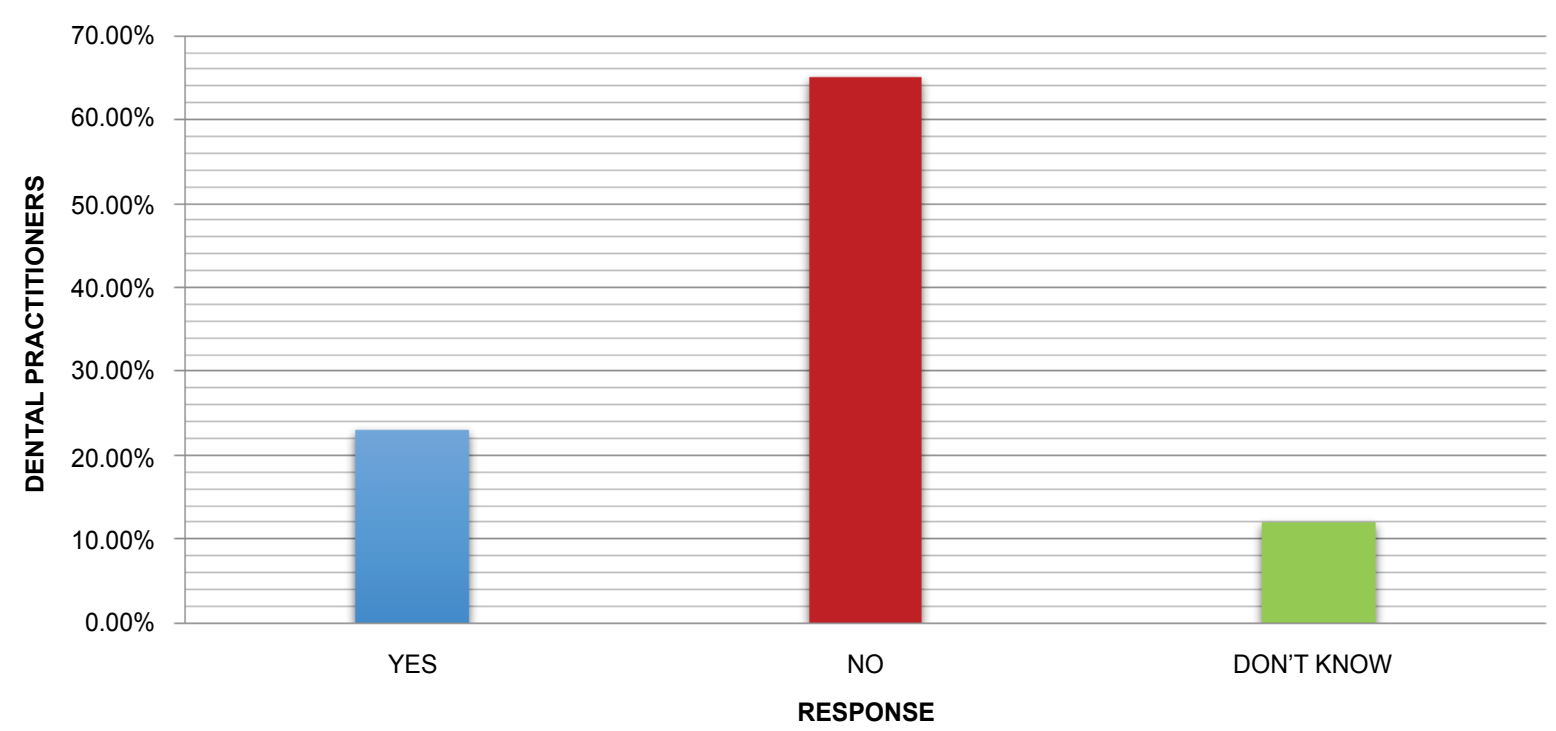

Figure 6: Knowledge concerning prevention and detection of oral cancer.



Figure 7: Change within the mouth associated with oral cancer. 


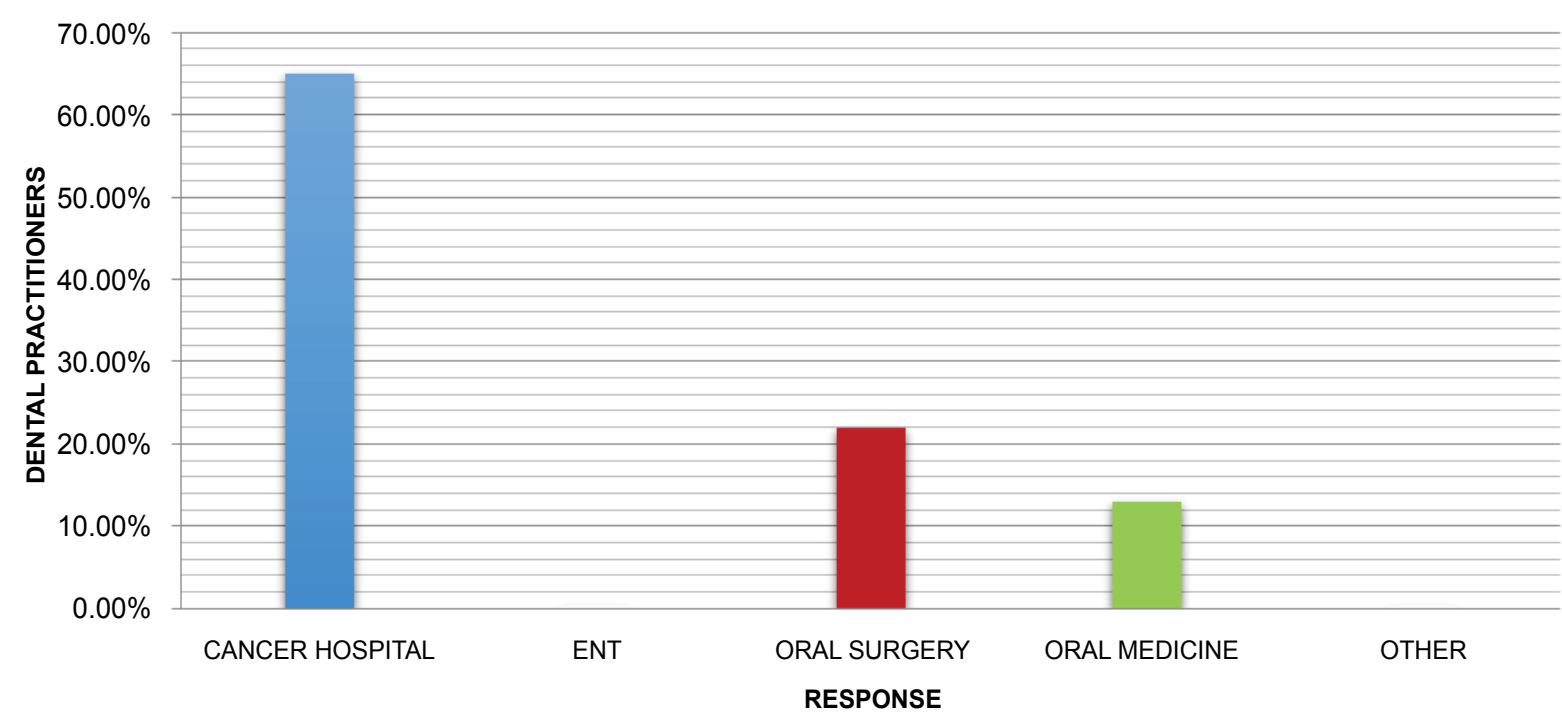

Figure 8: Referral point for oral cancer.

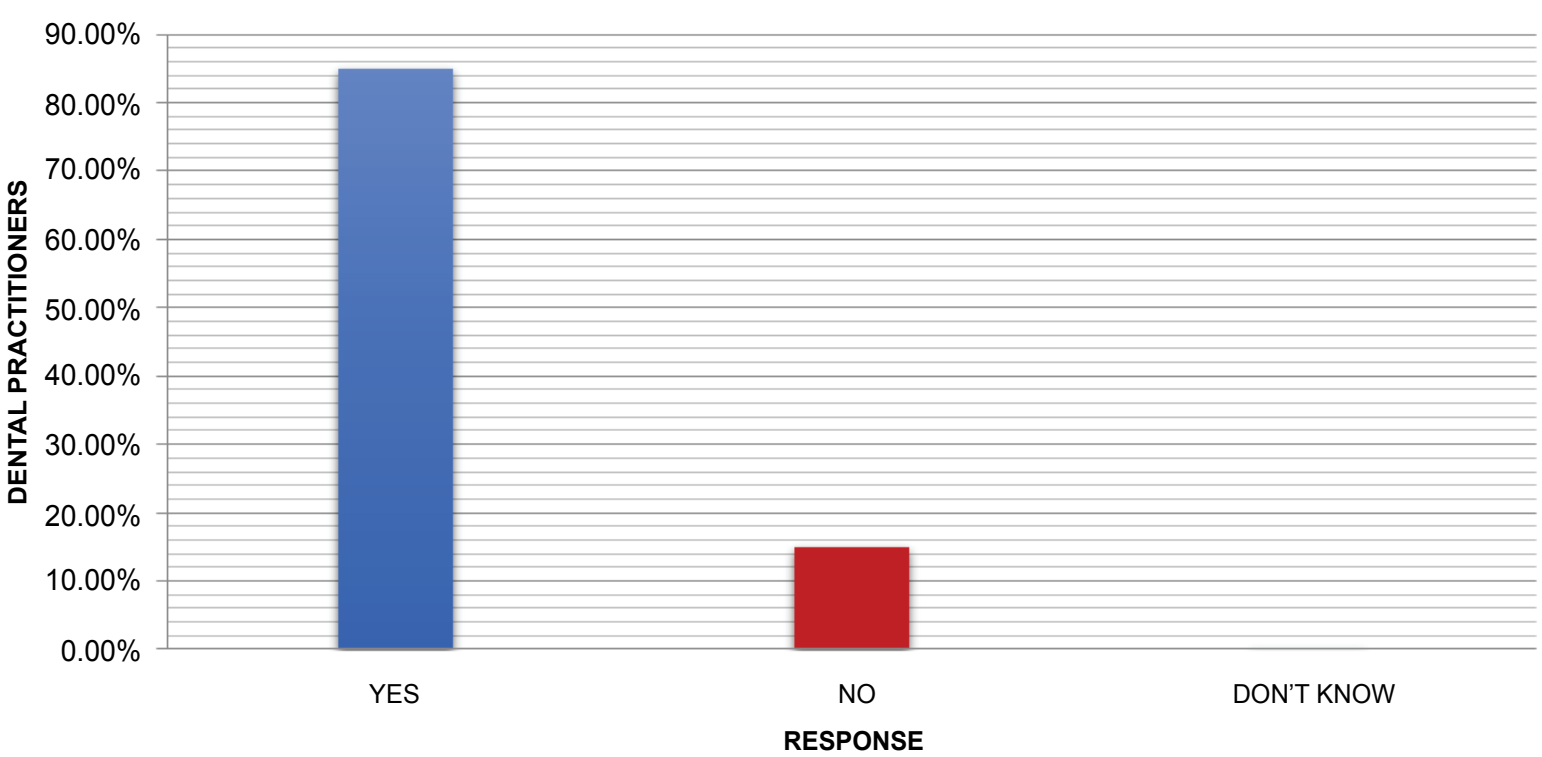

Figure 9: More information or training on oral cancer.

further training and educational programmes regarding oral cancer (Figure 8 and Figure 9).

\section{Discussion}

Early detection is the single most critical intervention influencing survival of patients with oral cancer. The oral cavity is easily accessible and can be examined with little discomfort. Dentists, as primary care providers, can easily incorporate the screening protocol into their routine examinations. M. Greenwood and R. J. Lowry [4] conducted a study to compare the knowledge of oral cancer and related issues in general dental and general medical practitioners. It was found that dental practitioners were significantly more likely to have diagnosed cases of oral cancer than medical practitioners. Important differences arose between the groups in terms of risk factor knowledge and clinical examination.

Joanne B. Clovis, et al. [5] conducted a study to determine the knowledge and opinion of dentists regard- ing oral cancer in British Columbia and Nova Scotia. It was found that many dentists were aware of their lack of knowledge and were not confident about their knowledge and practices suggesting strong need of educational interventions for practitioners and dental students. They also found that $90 \%$ dental practitioners considered tobacco as main risk factor for oral cancer whereas in our study $23 \%$ considered tobacco and $53 \%$ considered smoking as main risk factor for oral cancer. In similar study $46 \%$ of the dental practitioners considered that their knowledge regarding oral cancer was insufficient whereas in our study $65 \%$ of the dental practitioners considered their knowledge regarding oral cancer was insufficient.

L. M. Carter and G. R. Ogden [3] conducted a study to assess General Medical Practitioner's (GMPs) and General Dental Practitioner's (GDPs) awareness of prevention and early detection of oral cancer and concluded that GMPs were less likely to examine patients' oral mu- 
cosa routinely and there is need for improved education of general medical practitioners on oral cancer as compare to general dental practitioners. They also found that $95 \%$ of the dental practitioners routinely examined oral mucosa of the patients who were under high risk categories which was almost in accordance with our study in which $83 \%$ of the dental practitioners routinely examined oral mucosa of the patients who were under high risk categories. In similar study $80 \%$ associated ulceration with oral cancer whereas in our study 39\% associated non-healing ulcer with oral cancer. Majority of them chose oral medicine as referral point but in our study $66 \%$ chose cancer hospital as referral point.

Gabriela Decuseara, et al. [6] conducted a study to assess dentists knowledge, opinions and practices regarding oral cancer. It was also found that $55 \%$ of the dental practitioners identified older age as a potential risk factor for development of Oral cancer whereas in our study $67 \%$ considered risk of oral cancer increases with age. Dentists are underutilized in the prevention and early detection of oral cancer, and one of the barriers is lack of training.

Warnakulasuriya $\mathrm{K}$ [7] conducted a study in which he found that $84 \%$ of the dental practitioners perform screening of the oral mucosa routinely in practice whereas in our study $76 \%$ of the dental practitioners routinely examined oral mucosa of their patients.

Alice M. Horowitz, et al. [2] conducted a study to determine US dentist's opinions and practices regarding oral cancer prevention and early detection and found that $50 \%$ dental practitioners indicated an interest in taking continuing education course regarding oral cancer whereas in our study $85 \%$ showed interest in further training regarding oral cancer. There is need for dentists to determine their patients risks for oral cancer and provide routine and comprehensive oral cancer examination which is in accordance with our study.

A study conducted by S.S. Prime, et al. [8] showed that there is an increase in the incidence of oral cancer in those syndromes associated with defects in caretaker genes. In xeroderma pigmentosum, Bloom syndrome, ataxia telangiectasia and Fanconi's anaemia, second primary malignancies of the oral cavity appear to occur more commonly than might be expected. These syndromes are characterised by genetic instability and whereas xeroderma pigmentosum has been attributed to a defect in DNA repair, ataxia telangiectasia, Bloom syndrome and Fanconi's anaemia are inherited conditions of chromosomal instability. Genes are important in oral cancer development and behaviour. So it is very important for dental practitioners to know that genetic instability, about which is known very little in relation to oral cancer, may be of fundamental importance.

A survey done by Sitheeque, et al. [9] on awareness of oral cancer and precancer among final year medical and dental students of Universiti Sains Malaysia showed the dental students do not have differed significantly in some areas of knowledge from their medical colleagues. The authors pointed to a necessity to strengthen these aspects of medical and dental undergraduate curricula. Similar studies were done by Alami, et al. [10] to assess the knowledge of oral cancer among recently graduated medical and dental professionals in Amman, Jordan. The results revealed an inadequate level of knowledge of oral cancer among the study population, with significant differences between the dental and medical professionals. The authors suggested a need for improvement of the undergraduate curriculum in oral cancer in both medical and dental schools and for the provision of postgraduate and continuing education on this topic. The current survey also reveals that further training is required for dental professionals to increase awareness of oral cancer and its associated risk factors and to strengthen the practitioners' abilities to diagnose potentially cancerous intra-oral lesions. Practitioners must have current knowledge of risk factors for oral cancer, the factors that do not pose any risk, and diagnostic procedures to assess patient health, to enable them to provide oral cancer examination and to assist patients in reducing their risk through tobacco cessation counselling and other patient education.

Educational strategies should be focused at providing current information on risk factors, oral examinations, adjunctive diagnostic aids including biopsy and frequent patient referrals, thus facilitating early detection of oral cancer. It is necessary to emphasize the importance of oral soft tissue examination in the undergraduate curriculum and provide opportunities for dental practitioners to ensure that such examinations become a routine practice and arrive at an accurate diagnosis. In addition to providing information in booklets and digital videodisks, diagnostic evaluation of oral lesions and palpation of lymph nodes in patients, as well as demonstration of biopsy techniques are recommended which are bound to have the most immediate applicability to clinical practice. Attendance of continuing educational programs on oral cancer awareness organized by Dental Council should be made mandatory for practicing dental practitioners.

The study has some limitations that should be taken into consideration. The study was conducted on dental practitioners in Bhopal city and may not be generalized to other regions. In addition, the data presented here is self-reported, and some of the respondents may provide extreme responses than others, due to the motivations and beliefs of the practitioners, and might be subjected to recall bias. However, we believed that the practitioners were honest to provide appropriate responses and national level multifaceted studies are further needed to assess dental practitioner's knowledge about oral cancer. 


\section{References}

1. Sharma S, Satyanarayana L, Asthana S, Shivalingesh $\mathrm{K}$, Goutham BS, et al. (2018) Oral cancer statistics in India on the basis of first report of 29 population-based cancer registries. J Oral Maxillofac Pathol 22: 18-26.

2. Horowitz AM, Drury TF, Goodman HS, Yellowitz JA (2000) Oral pharyngeal cancer prevention and early detection. Dentists opinions and practices. J Am Dent Assoc 131: 453-462.

3. Carter LM, Ogden GR (2007) Oral cancer awareness of general medical and general dental practitioners. Br Dent J 203: 10.

4. Greenwood M, Lowry RJ (2001) Oral cancer: Primary care clinician's knowledge of oral cancer: A study of dentists and doctors in the North East of England. Br Dent J 191: 510512.

5. Clovis JB, Horowitz AM, Poel DH (2002) Oral and pharyngeal cancer: Knowledge and opinions of dentists in British Columbia and Nova Scotia. J Can Dent Assoc 68: 415-420.
6. Decuseara G, MacCarthy D, Menezes G (2011) Oral cancer: Knowledge, practices and opinions of dentists in Ireland. J Ir Dent Assoc 57: 209-214.

7. Warnakulasuriya KA, Johnson NW (1999) Dentists and oral cancer prevention in the UK: Opinions, attitudes and practices to screening for mucosal lesions and to counselling patients on tobacco and alcohol use: Baseline data from 1991. Oral Diseases 5: 10-14.

8. Prime SS, Thakker NS, Pring M, Guest PG, Paterson IC (2001) A review of inherited cancer syndromes and their relevance to oral squamous cell carcinoma. Oral Oncol 37: $1-16$.

9. Sitheeque M, Ahmad Z, Saini R (2014) Awareness of oral cancer and precancer among final year medical and dental students of Universiti Sains Malaysia (USM), Malaysia. Arch Orofac Sci 9: 53-64.

10. Alami AY, El Sabbagh RF, Hamdan A (2013) Knowledge of oral cancer among recently graduated medical and dental professionals in Amman. Jordan. J Dent Educ 77: 13561364. 


\section{Annexure}

\section{People's Dental Academy}

\section{Department of Oral Medicine and Radiology}

This questionnaire has been designed with the purpose of using the information to consider ways of improving prevention, early detection and referral of oral cancer by doctors and dentists.

Age (................yrs) Sex-Male/female.

Qualifications: BDS/MDS

\begin{tabular}{|c|c|c|}
\hline S.No & Questions & Tick Anyone \\
\hline 1. & Do you examine patient's oral mucosa routinely? & YES/DON'T KNOW/NO \\
\hline 2. & Do you screen the oral mucosa if the patients are in high risk categories? & YES/DON'T KNOW/NO \\
\hline \multirow[t]{5}{*}{3.} & \multirow[t]{5}{*}{ What would you consider as risk factors for oral cancer? } & a) Smoking \\
\hline & & b) Smokeless tobacco \\
\hline & & c) Alcohol \\
\hline & & d) Family history \\
\hline & & e) Poor oral hygiene \\
\hline 4. & Does risk of Oral Cancer increase with age? & YES/DON'T KNOW/NO \\
\hline \multirow[t]{4}{*}{5.} & \multirow[t]{4}{*}{ As regards diagnosing oral cancer from clinical appearance, how do you feel? } & a) Very confident \\
\hline & & b) Confident \\
\hline & & c) Unsure \\
\hline & & d) Very unsure \\
\hline 6. & $\begin{array}{l}\text { Do you feel that you have sufficient knowledge concerning prevention and } \\
\text { detection of oral cancer? }\end{array}$ & YES/DON'T KNOW/NO \\
\hline \multirow[t]{4}{*}{7.} & \multirow[t]{4}{*}{ What changes within the mouth would you associate with oral cancer? } & a) Growth of abnormal tissue \\
\hline & & b) Non-healing ulcer \\
\hline & & c) Red patch \\
\hline & & d) White patch \\
\hline \multirow[t]{5}{*}{8.} & \multirow[t]{5}{*}{ Where would you refer a patient if you suspected an oral malignancy? } & a) Cancer hospital \\
\hline & & b) ENT \\
\hline & & c) Oral Surgery \\
\hline & & d) Oral medicine \\
\hline & & e) Other \\
\hline 9. & Would you like more information or training on oral cancer? & YES/DON'T KNOW/NO \\
\hline
\end{tabular}

Your answers will be treated as strictly confidential; Thank You for Your Cooperation.



